\title{
Noun Formation in Standard English and Modern Standard Arabic: A Contrastive Study
}

\author{
AbdulMahmoud Idrees Ibrahim \\ P. O. Box 1432, English Language Department, Faculty of Education, Alza'em Alazhari University, Sudan \\ Email: amdid@maktoob.com
}

\begin{abstract}
This paper focuses on analyzing and contrasting the processes of noun-formation in both Standard English (English) and Modern Standard Arabic (MSA), in order to reveal the similarities and differences between them and their potential productivity for pedagogical purposes. The data for the present study has been collected from different sources, compiled and analyzed in terms of morphology, productivity and semantic indications of the different processes of noun-formation in both languages. It is found that both English and MSA reveal a common linguistic phenomenon in noun-formation processes as well as their exploitation of the language by forming productive rules and patterns. The similarities are found in some general universals, such as affixation, compounding, blending, onomatopoeia, borrowing, diminutives, conversion and acronyms. Every language has regular rules for noun-formation, but some irregular forms may also exist in both of them.
\end{abstract}

Index Terms - word-formation, noun-formation, contrastive linguistics, morphology

\section{INTRODUCTION}

Noun-formation as a sub-process of word-formation is a complex area of research in both Standard English (Indo-European language, henceforth referred to as English) and Modern Standard Arabic (Semitic language, henceforth referred to as MSA). Noun-formation in English has the same problem of word-formation. Bauer declares that "Unfortunately, there is little agreement on the methodology or basic theoretical background for the study of word-formation that the field is currently a confused one" (Bauer 1983: 01). Thus, there is no single theory of noun-formation in English, and consequently no definite procedure for compiling the data to be gathered.

The present study is an attempt in contrastive analysis aimed at identifying, analyzing, and contrasting the process of noun-formation and its potential productivity. The study also aims at revealing the possible universals of the two languages in the field of noun-formation, and to determine as much as possible the similarities and differences between them.

\section{REVIEW OF LITERATURE ON CONTRASTIVE ANALYSIS}

It is worth mentioning here, that CA is still in use and of use in language teaching in spite of all the criticisms made against it. There have been many CA-based studies where their predictions have been confirmed by empirical results (George 1972: 27). The research estimates that nearly one-third of all errors made by the L2 learners are due to interference from the Mother Tongue (MT).

Hamid (1997) has conducted CA on Apposition in English and Arabic. He conducted a composition test on first-year university students and found out that a large number of the errors were committed as a result of MT interference. Mahmoud (1995), who also conducted CA on concord in both English and Arabic; he did not conduct a test, but made some predictions relying on the strong version of the CA hypothesis. He found that the MT interference causes many errors.

Thus, many of these studies maintain that MT interference is one of the strongest variables that influence FL learning and consequently CA still seems to have place in foreign language teaching methodology.

\section{NOUN-FORMATION IN ENGLISH}

Noun-formation is a sub-field of word-formation, which is a branch of lexical morphology, defined as "The study of morphological relations among lexemes" (Matthews, 1991: 37). Noun-formation has not been tackled separately as a subject in itself, but only within the broader subject of 'word-formation, and there is no separate methodology to be followed. "There is no one body of accepted doctrine of the subject to be followed, so that researchers are largely having to make up their own theory and procedures as they go along" (Bauer, 1983: 6).

Noun-formation is not an exception to the word-formation process; it follows the same morphological rules. In noun-formation classification, there are compounding, the resultant combination of two (or more) morphemes. The meaning of compounds cannot be predicated from the meaning of their individual morphemes. There is also affixation or derivation, which forms nouns with derivational affixes. Conversion is a functional shift of a word; if it is a verb, it 
may act as a noun without any change of its morpheme. Then there is the process of unpredictable noun-formation; the first of this type is clipping, where the word is made smaller without any change of its meaning or class form. Acronyms, on the other hand, are nouns derived from the initial letters of several words, as in NASA. Blending is similar to compounds, but usually combines shortened forms of two or more morphemes or words. The final type of unpredictable processes is word-manufacture, which refers to the process of arbitrarily selecting any acceptable sequence of sounds and using it as the name of an object, as in 'Kodak'. Borrowing is the most prolific source of additions to the vocabulary of English and it is of two types-to borrow the word as it is or for that to be translated (calque). The final process in noun-formation is reduplication by repeating an item with a change in the initial consonant or with a change in the middle vowel. Onomatopoeia is one of the oldest methods of word formation in English. Multiple-formation is a result of applying two processes of formation each one of them is compulsory for forming the word.

These processes of noun-formation in English may also appear in other languages like Arabic, as it well be seen in the next chapter.

\section{NOUN-FORMATION IN MODERN STANDARD ARABIC}

Word-formation in the Arabic language depends on the consonants, which represent the root of the words formed. Most of the Arabic words have a tri-consonantal root, but the addition of consonants and vowels gives many morphological patterns as well as many morphological categories. These derivatives constitute the large body of the language and all the derivatives of the same root have semantic relationships that are potentially founded in their root. However, there are many controversies among the grammarians about which are derived from which. All these controversies among the old and contemporary Arabic grammarians show that the Arabic language is a derivational language. Noun-formation in Arabic has the lion's share in the lexicon; actually, this is attributed to the Kufa School, which claims that the verb is the origin of all the derivatives.

The traditional grammarians classified derivation into four classes:

- The small derivation

- The big derivation

- The bigger derivation

- The biggest derivation

The small derivation has the prime role in increasing the vocabulary among all types of noun-formation and it has many kinds of sub-derivative, which play many interrelated functions. The big derivation depends on the shift and substitution of the three letters in six different ways to give six words or nouns, which have a semantic relationship. But the third type, bigger derivation, depends on replacing a sound or a letter in the place of the other in the same noun word to give the same meaning as in [hadi:1] and [hadi:r]. The fourth one is the biggest derivation, which is called by many grammarians 'blending'. It is not a very prolific way of producing new words in Arabic, but nowadays there is this tendency in translating the modern terms.

The other type of noun-formation is the compound nouns, the resultant of compounding two or more morphemes to form one to indicate another or additional meaning. Compound nouns in Arabic are of three types: genitive, predicative and synthetic compounds.

Borrowing is a universal phenomenon and Arabic language is not an exception. Arabic borrowed a vast body of vocabulary from the neighboring nations then and is still borrowing, especially the terms of modern civilization. Borrowing is dealt with in three classes or types according to linguistic norms in Arabic. These types are: the Arabized, the postclassical and the slang, which is used by the common people. Arabic language is also a good exporter of words to nearly all the languages of the world. The diminutive is also considered a type of derivation and it has a sub-type called diminutive elision, which is used mostly for courtship and poetic necessities. Imitation (Onomatopoeia) is the oldest process of noun-formation; it represents sounds.

\section{THE MORPHOLOGICAL PATTERN}

Two traditional schools of grammar established most of MSA linguistic literature. One of them is the Kufa School and the other is the Basra school. The former believed that the verb is the origin of derivatives, simply because the human being apprehends the action before the abstract noun; therefore the 'abstract noun' is a derivative but they do not deny the existence of some derivatives from proper nouns. On the other hand, the Basra school believes that the abstract noun is the origin and the verb is a derivative, simply because the abstract noun indicates the action without any reference to the time of the action.

Both of the two schools in agreement that most of the Arabic lexis have a trilateral root (f 9 l) (see figure 1 and 2), which indicate the potential action of all its derivatives. The root (f 9 l) was used by Alkaleel- Bin-Ahmed as a standard norm or criterion for rhyming in poetry. The morphologists used this norm as a morphological scale to distinguish the different processes that the word form may undergo, in other words, what affixes are added, inflexions, tiers, and what letters of the root are shifted or deleted. Accordingly, every change that happens in the word form must be adjusted in the morphological pattern. 


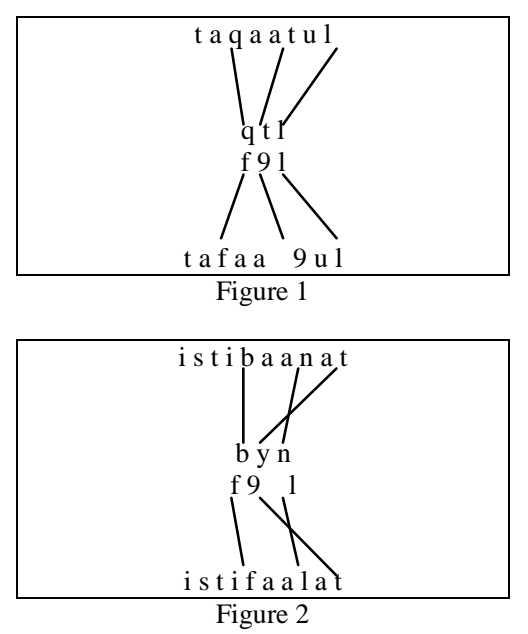

As it is obvious, (taqaatul) shows neither deletion nor shifting in the triliteral root. (istibaanah) shows both processes: deletion and replacive shifting, the [ya] of the verb (bayan) is deleted, consequently the [9] of the morphological scale is deleted also and accordingly a suppletive morph (t) is added at the end of the noun.

The application of MSA morphological pattern rules is not difficult. In this respect Hudson (1985: 86-7) states that the traditional Semitic grammarians have satisfied themselves with a few examples to show the manner of derivation, but naturally enough the examples are quite effective, the patterns are quite clear, and there is no evidence that root and pattern morphologies are difficult to learn. However (Hudson) on the same topic applies the derivational rule on the root [k t b] and he gave many examples which do not really exist in Arabic and it is not reasonable to apply the rule to produce many stems without regarding the restrictions of MSA root productivity. For example, the derived [takattab] and [tuku:tib] which do not exist in MSA, but [takabtab] is used instead of them. In addition, he uses CC cluster at the beginning of MSA words, like [ktatab] for [inkatab]. But he is mistaken no Arabic word begins with such a cluster, but it can permit VCC or CVC initially.

\section{CONTRASTIVE ANALYSIS}

\section{A. Method of Comparison}

Having discussed and explained the processes of noun-formation in the two languages (English and MSA), we will discuss with the similarities and differences in the processes of noun-formation in both English and MSA, without going into the details of the rules, which have already been discussed earlier. Tables will be drawn when it is appropriate for the contrastive study, or when it serves the purpose well, and a brief explanation will be given for the aspects of similarities and differences. To show the similarities or differences between the two languages, the one-to-one correspondence method is followed.

\section{B. Derivation (Affixation)}

English (as an Indo-European language) and Arabic (as a Semitic language) are completely different in their linguistic forms, but they share the same universals of language. In the following section, these universals of languages will be discussed to explain their similarities and their differences to serve the aims of the study.

1. Similarities

English and MSA share the same universals of language, for example, similarities of affixation terms.

TABLE 6.1

\begin{tabular}{|c|c|}
\multicolumn{2}{|c|}{ CLASS-MAINTAINING PREFIXES } \\
\hline English & MSA \\
\hline All prefixes in & $\mathrm{ma}$ \\
& $\mathrm{mi}$ \\
\hline
\end{tabular}

Thus, all prefixes of nouns in English and MSA are class maintaining. The function of a prefix in both languages is to change the meaning of the base to which it is added.

TABLE 6.2

CLASS -MAINTAINING SUFFIXES

\begin{tabular}{|c|c|}
\hline In English & In Arabic \\
\hline \multirow{2}{*}{ Suffixes forming abstract nouns } & Iyyah \\
\cline { 2 - 2 } & $\mathrm{t}$ \\
\hline
\end{tabular}


Although this Table shows the similarities according to the universals of language, it is not very precise, because a process of overlapping happens according to the differences between the two systems. Whatever the case, the above suffixes are similar in forming abstract nouns in both the languages.

Affixes can be classified with reference to the word-class that is produced when they are added to a base; alternatively, they can be classified according to the grammatical class of the base to which they are added. The following tables summarize these ideas.

TABLE 6.3

AFFIXES FORMING ABSTRACT NOUNS

\begin{tabular}{|c|c|c|}
\hline \multicolumn{2}{|c|}{ English } & \multirow{3}{*}{$\begin{array}{c}\text { MSA } \\
\text { All the verbal noun affixes } \\
(\mathrm{s}, ?, \mathrm{t}, \mathrm{m}, \mathrm{n}, \mathrm{y}, \mathrm{h}, \mathrm{a}, \mathrm{l}, \mathrm{w})\end{array}$} \\
\hline -age & mileage & \\
\hline -ery & machinery & \\
\hline -dom & freedom & \multirow{4}{*}{$\begin{array}{c}\text { The prefix [iyyah] in the abstract nouns } \\
\text { as in (insaaniyyah }\end{array}$} \\
\hline -hood & brotherhood & \\
\hline -ism & humanism & \\
\hline -ship & friendship & \\
\hline
\end{tabular}

The suffix -ism in English usually matches the suffix [iyyah] in Arabic, but -dom, and -ery sometimes match the same suffix, as in kingdom and slavery (but this is restricted to Arabic sense).

TABLE 6.4

AFFIXES FORMING CONCRETE NOUNS

\begin{tabular}{|c|c|c|}
\hline \multicolumn{2}{|c|}{ English } & Arabic \\
\hline -age & orphanage & \multirow{7}{*}{$\begin{array}{l}\text { All the small derivation } \\
\text { sub-types affixes ( } \mathrm{m}, \mathrm{w}, \mathrm{y}, \mathrm{a} \text {, } \\
\text { t) which materialized in } 5\end{array}$} \\
\hline -eer & engineer & \\
\hline -er & villager & \\
\hline -ess & lioness & \\
\hline -ette & leatherette & \\
\hline -let & streamlet & \\
\hline -ling & nursling & \\
\hline
\end{tabular}

The $[\mathrm{m}]$ always functions as a prefix, but the $[\mathrm{t}]$ functions as a suffix and the others are all infixes.

TABLE 6.5

NOUN AFFIXES HAVING A DEVERBAL FUNCTION

\begin{tabular}{|c|c|c|}
\hline \multicolumn{2}{|c|}{ English } & MSA \\
\hline -al & arrival & Verbal noun [wusu:l] \\
\hline -ant & assistant & Agentive noun [musaa9id] \\
\hline -ation & generation & Verbal noun [tawli:d] \\
\hline -ee & kissee & Patient noun [muqabbal] \\
\hline -er & killer & Agentive noun [qaatil] \\
\hline -or & actor & Agentive noun. [muma $\theta \theta i 1]$ \\
\hline -ment & movement & Verbal noun [harakah] \\
\hline -ure & closure & Verbal noun [nihaayah] \\
\hline
\end{tabular}

We can conclude that the similarities of affixation function in English and Arabic give a certain semantic indication if they are class-maintaining affixes or class-changing, or if they form concrete nouns or the ones which have a deverbal function. Moreover, all the derivational affixes occur closer to the root than the inflexional affixes.

2. Differences

The main differences between English and Arabic in Affixation are:

There are no infixes at all in English, while the Arabic language depends mainly on infixes to make new derivative lexemes. Suffixes in Arabic are restricted in their use to certain situations, such as the feminine marker [t] or the suffix [iyyah] which forms abstract nouns from verbal or concrete nouns, while the English language tends to use suffixes in a productive manner to generate a huge corpus of nouns. Prefixes, on the other hand, in Arabic seem to be limited; they are just six (a, t,?, in, ist, ma/ mu), while the English prefixes are numerous and varied. The affixes in Arabic may often be realized orthographically with one letter, but the English affixes are often realized with more than one letter.

\section{Compound Nouns}


TABLE 6.6

COMPOUND NOUN PATTERNS

\begin{tabular}{|c|c|c|c|}
\hline English compound patterns & Examples & MSA compound patterns & Examples \\
\hline N. + N. & Beehive & Genitive and predicative compound & Abdullah Alxayru-Nazil \\
\hline N. + N. & Breakfast & Predicative compound & Fataha-Allah \\
\hline N. + V. & Sunshine & & \\
\hline V. + V. & Make-believe & & \\
\hline Adj. + N. & Software & & \\
\hline Particle + N. & Overseas & & \\
\hline V. + particle & Drop-out & & Hadramawt \\
\hline Phrase Compound & Son -in -law & & \\
\hline Special group of compound & Telephone & synthetic compound & \\
\hline
\end{tabular}

\section{Similarities}

Table 6.6 shows all the English types of compound noun and their equivalents in MSA. Apparently, as it is seen in the table 6.6, there are three types in English and three in MSA, but the predicative type plays the role twice; this is because it has two sub-types. The similarity is only on the surface structure; noun + noun, verb + noun, and a special group of compounds like synthetic compound in MSA. The only aspect of similarity is that all types of compounds can be exocentric according to the semantic criterion.

\section{Differences}

The differences are obvious from Table 6.6, especially for those English types, which have no equivalents in MSA. The other differences are implied in the different semantic criteria for every type in both languages.

3. Semantic Criteria

All the MSA compound nouns are exocentric (bahuvrihi), since the compounds are hyponyms of some unexpressed semantic heads. The compounds in this case are considered metaphorical or synecdochic. But, for the genitive compound, the semantics is very complicated, whereas the English compound can follow all the semantic criteria, as in these examples:

$$
\begin{aligned}
& \mathrm{N}+\mathrm{N}=\text { armchair endocentric } \\
& \mathrm{N}+\mathrm{N}=\text { maidservant appositional } \\
& \mathrm{N}+\mathrm{N}=\text { Alsace-Lorraine copulative }
\end{aligned}
$$

4. Productivity

Compounding in English is a very productive process. If we compare it with the compounding process in Arabic, we find that English language depends mainly on this process to enlarge and increase its vocabulary, whereas this process in Arabic does not do so to the same extent.

\section{Conversion}

Conversion, as a change in the function of a word from a grammatical class to another, is well known to English grammarians and most of their grammar books do not neglect this phenomenon. But, for the Arabic grammarians, conversion has no place in their writings, because conversion in Arabic language is not regular and not productive.

The very few examples in MSA, which may show similarities between the two languages, are those examples of verbs that are used as proper nouns like [Ta9iz and Yanbu9] names of cities, [Ya9rub and Yald3ub] are names of persons, or the superior comparison noun [a f 9 a l] and the adjunct noun [a f 9 a 1]. Also Arabic does as English in converting common noun to proper noun, e.g., Osama the proper noun, was once a common noun for the lion.

\section{E. Unpredictable Formation}

According to Bauer's classification (see 4), this process has four types: clipping, acronyms, blending, and word-manufacture. Are all these processes realized in Arabic?

1. Clipping

It is a process whereby a lexeme (simple or complex) is shortened. The MSA does not have this process at all. Therefore, the non-existence of this process in Arabic is proof of Aronoff's claim (1976: 20), "that this process depends upon orthography to greater or lesser degree, and thus cannot be universal, since it is not a prerequisite to linguistic behavior."

\section{Acronyms}

It is the process of using the initial letters of a phrase as one word . This process of forming nouns saves time and space. The MSA did not use this process before, but lately tends to use it, either by verbatim translation (Arabization) or by creating a new word from a longer word or phrase, as in [mud3] for [mud3allad], [hamaas] and [mawd3] acronyms for political parties in Yemen and Palestine.

There is no difference in this process between the two languages. Since it is practical and seems to be productive, a number of acronyms will soon be found in MSA.

3. Blending

The biggest derivation is a synonym of blending, and it is well known in both English and Arabic.

a. Similarities 
Both languages use the blend word to refer to a pair or group of words realizing their features.

Blending in both languages has the purpose of giving additional meaning. Blending in both languages seems to be confuses with affixation or compounding. In both languages, blending is an unpredictable process.

The Arab linguists classify the blend words into four types; although the English ones do not do the same, but the English language matches the Arabic classification (see Table 6.7).

TABLE 6.7.

BLENDING REALIZATION

\begin{tabular}{|c|c|c|c|}
\hline \multicolumn{2}{|c|}{ Type of blending } & Examples in Arabic & Examples in English \\
\hline 1 & verbal & basmalah & Guesstimating \\
2 & descriptive & dibtir & Balloonatic \\
3 & denominative & d3almu:d & Slanguage \\
4 & attributive & tabraxzi: & Oxbridger \\
\hline
\end{tabular}

Here the verb is used as a noun to fit the study of noun-formation.

b. Differences

The main difference between the two languages is that in English the process of blending is very productive, but in Arabic it seems to be limited to a few examples, if we do not take into account Ibnu-Faris' efforts in this field.

4. Word Manufacture

There are no differences in the use of this process in both English and MSA. But this process has no place in the Arabic grammar books, simply because this process of noun-formation did not originally exist in Arabic language. Even those nouns which we find in English and which are considered to be examples of manufacture have been domesticated in Arabic with their original sounds. For example Teflon, macron, Orlon and even Kodak are found in Arabic with the same pronunciation, with very slight modification according to the Arabic accent.

\section{F. Borrowing}

Borrowing is a universal phenomenon; therefore, all languages tend to use it as a way of increasing its vocabulary. Languages influence each other for many reasons, but the response is actually different in the case of Arabic and English. The following table shows the similarities and differences in the response for borrowed words.

TABLE 6.8

BORROWING CLASSIFICATIONS

\begin{tabular}{|c|c|}
\hline English & MSA \\
\hline \multirow{2}{*}{ Loan-word } & Arabized \\
\cline { 2 - 2 } Calque & Almuwallad \\
\cline { 2 - 2 } & The slang \\
\hline
\end{tabular}

The above table shows two types of borrowing in English vis-à-vis their counterparts in MSA. Although, apparently, they do not seem to be equal, they are equal irrespective of the different terms used.

(1) What is called Loan-word in English matches with all of the three types in MSA? That is because each of the Arabized, Almuwallad, or the slang can realize what is termed in English by 'Loan-word', the process of borrowing a foreign word as it is pronounced in its original language, but with slight modification to fit the morphophonological rules of the borrowing language.

(2) What is called calques can match 'Almuwallad' in MSA. One may ask why 'Almuwallad' matches the two English types of borrowing. This is simply because some Arab linguists define it as: “.... a word of Arabic origin given a new meaning by derivation, metaphor, or by semantic shift..." (Khaleel, 1978: 219). This definition stands by or serves the translation process that matches what is called calque in English. For example 'skyscraper' is an example for calques, and [naatihatu-s-sihaab] an Arabic word which gives the same meaning exemplifies what is called 'Almuwallad'.

Thus, according to the different definitions of Arab linguists, 'Almuwallad' as a term can serve to match the two English terms. Irrespective of the ambiguity of the Arab linguists' definition of 'Almuwallad' no differences in this process exist between them, except that Arabic tends very much to derive from these borrowed words.

\section{G. Reduplication}

This process of noun-formation, which is found in English, is not found in Arabic at all. But some of the juxtaposition compounds in Arabic can show some similarity with this English type. For example as, in [bayta-bayt] for the neighbouring houses, or [ Jaðara-maðara] for helter-skelter (MSA uses it as a noun and English uses it as an adverb).

\section{H. Multiple Functions}

This process of noun-formation in English is a result of applying two processes, first clipping and then adding the diminutive suffix ' $y$ '. Multiple function as a noun-formation process is found in Arabic, but in a different way. This process in English matches the diminutive elision in MSA. The diminutive elision undergoes the same process of multiple function, first contraction and then insertion of the diminutive infix 'ay'. 


\section{Onomatopoeia}

This process depends on the attempt to imitate some characteristic sound of a creature or an object, which is being referred to. This process of noun-formation is the oldest process and it has generated numerous nouns in both languages, English and MSA. Both languages share the same phenomenon, but they have subjected the nouns they formed to their respective phonological rules.

\section{CONCLUSION}

Noun-formation is a complex process in both languages, which requires adequate mastery of the rule to control and apply the process of formation. English and MSA show similarities as well as differences, according to one process or another. However, both languages have some shared general universals. This is clear in their attitude towards the classification of noun-formation, especially in affixation, compounding, blending, onomatopoeia and borrowing (see table 7.1). Acronyms and word manufacture appear in MSA, and the influence of foreign language and the output of both processes should be considered as a result of borrowing.

The general similarities that appear in both languages in affixation manifest similar taxonomic types, such as the agentive nominalization, patient noun, instrument nominalization and the superior comparison. Both languages use prefixes and suffixes in noun-formation. There are no infixes in English, but MSA depends on them more than the prefixes and suffixes in forming a large corpus of words. Table 7.1 shows the realization of each process in both languages.

TABLE 7.1

PROCESSES OF NOUN-FORMATION

\begin{tabular}{|c|c|c|}
\hline NAME OF PROCESS & ENGLISH & MSA \\
\hline Compound-noun & $\sqrt{ }$ & $\sqrt{ }$ \\
\hline affixation & $\sqrt{ }$ & $\sqrt{ }$ \\
\hline blending & $\sqrt{ }$ & $\sqrt{ }$ \\
\hline acronyms & $\sqrt{ }$ & $\sqrt{ }$ \\
\hline clipping & $\sqrt{ }$ & X \\
\hline word-manufacture & $\sqrt{ }$ & $\sqrt{ }$ \\
\hline borrowing & $\sqrt{ }$ & $\sqrt{ }$ \\
\hline reduplication & $\sqrt{ }$ & $X$ \\
\hline conversion & $\sqrt{ }$ & $\sqrt{ }$ \\
\hline back formation & $\sqrt{ }$ & $X$ \\
\hline multiple-formation & $\sqrt{ }$ & $\sqrt{ }$ \\
\hline Onomatopoeia & $\sqrt{ }$ & $\sqrt{ }$ \\
\hline big derivation & $X$ & $\sqrt{ }$ \\
\hline bigger derivation & $X$ & \\
\hline
\end{tabular}

English depends mainly on compound nouns to increase its vocabulary, while MSA depends on derivation (affixation). Arabic distinguishes eight types of derivative to utilize the process of derivation fairly well. These eight types of derivatives represent a high percentage of nouns in MSA. Some of these types of derivatives are not found in English, such as the so-called the hyperbole nouns; this may suggest the Arabs' tendency towards exaggeration. English uses the affixes, which are considered to be foreign words to give new meanings, while MSA depends on intercalation of the letters to accomplish the same purpose.

In Arabic, compounding is not as important as it is in English, and this is clear in the corpus of its vocabulary. But MSA replaces this process with what are known as 'subject and complement', and also the descriptive compound. All compounds in MSA are semantically exocentric, while English offers four types of semantic in compounds.

Compounding in English is a very productive process in contrast with its counterpart in MSA. The written form of the compound noun in MSA has two forms: as one word or two (or more) separate words, while English has three ways of writing compounds: as one word, two (or more) separate words without a hyphen, or with a hyphen.

Conversion is an extremely productive way of producing new words in English. There do not appear to be morphological restrictions on the form that can undergo conversion, so that compounds, acronyms, blends, and derivatives can undergo this process, while MSA seems to be very conservative towards this process, and also few examples are found in MSA because of morphological restrictions.

The unpredictable formations in English: clipping, acronyms, blending and word-manufacture, are not found in classical Arabic or the early period of MSA, except for blending which was known in classical Arabic in a few words. Acronyms and word manufacture are now known in MSA with borrowing, but clipping (as in English) is an unknown process. Although blending was not productive in the classical period, during the Islamic period many words have been generated from longer ones. Nowadays, MSA takes to blending to meet the need for new terms for technology and science.

Borrowing as an international phenomenon is found in both languages almost in the same way: by borrowing the word as it is with a slight modification to fit the rules of the language, or by translating the meaning of the borrowed word. 
Finally, it can be said that both English (an Indo-European language) and MSA (Semitic language) reveal a common linguistic phenomenon in their classification of noun-formation processes as well as their attitude towards their utilization in the language by forming productive rules and patterns. This shows that every language has rules for forming its nouns, although some irregular forms may exist.

\section{A. Critique}

It is found that all noun-formation processes are generally rule-governed, but these rules are sometimes very complicated and some processes overlap and interpenetrate each other. The following examples will illustrate this notion.

In English, for example, the suffix 'er' as we have seen always denotes the agentive nominalization in the normal sense:

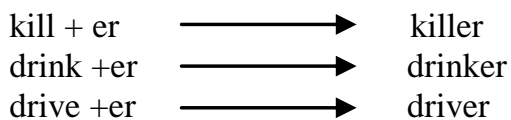

But in the following examples it denotes an instrument, as in:

curle + er $\longrightarrow$ curler

open + er $\longrightarrow$ opener

point + er $\longrightarrow$ pointer

We can also find in 'lover' denoting an experience or patient. We may ask whether this suffix is the only one in forming the agentive noun. The answer is actually 'no', because there are other suffixes or forms which denote this semantic trend.

These examples show different suffixes for the 'agentive noun':

return $+\mathrm{ee} \longrightarrow$ returnee

$\mathrm{Arab}+\mathrm{ist} \longrightarrow$ Arabist

solicit + ant $\longrightarrow$ solicitant

This explains that the English classification which depends on affixation to define and nominate a certain process of noun-formation is not very clear. It is better to define it according to semantic criteria, as we have seen in the MSA classification for the same process.

In the MSA classification for what is called 'agentive noun' and the 'adjunct noun', the demarcation between them is sometimes not clear, because both of them hold or share the same semantic features, especially the hyperbole patterns in the 'agentive noun' and some patterns in the adjunct noun, as in the following examples:
fa9i:1
fa9u:1
fa9il
hami:d
sabu:r
haoir
fa99aal
hammaad

These examples illustrate the duality of usage in both processes. Here also there is no need to use separate classification, although there are semantic correlations as well as patterns.

Compounds in both English and MSA have roughly the same concept, but if we take the MSA compound nouns, we will find that the overlapping is obvious with the blending process. We believe that in the compounding process the parts of the compound have to be present without omitting any letter, but some Arab linguists use it as a blending, as in the word [habqar] from [hab + qar] (see Abdu-t-Tawab,1994: 302). There is a question concerning English compounds: what rule governs the orthography of compounds, by hyphen, without it, or by making space between the parts?

The Arab grammarians (philologists) classified derivation into four classes: small, big, bigger and biggest. The last one is blending, but 'big' and 'bigger', which depend on a consequent replacement of the letter of the word and on metathesis, in the my opinion, add nothing to the vocabulary, because these words which are subjected to the treatment of generation are already found in the language. But what is called 'small' derivation is the most productive process and it is the most prevailing feature in MSA. It is an irony to call it 'small' derivation; it should be called biggest, largest, or even general derivation-this 'general derivation' was once a field for controversies for the Kufa and Basra grammarian school, as we mentioned previously. For me, the Kufa School is reasonable, because the verb is more flexible to lead the process of noun-formation, as we have seen above.

Some of the affixes in English transform to words, as in,-ism and -ist (Thakur, 1997:30). In compound nouns, every part of them is considered as an independent word. The question is "how can we define a word like racism, as a compound or as the result of affixation?" The demarcation between derivation and compound-formation needs more explanation.

Even though English and MSA share some linguistic universals, still the processes of noun-formation are not sometimes clear. It has been suggested, as Bauer (1983: 292) claimed, that "the only realistic way of gaining a proper understanding of the way in which word-formation works is by ignoring lexicalized forms and concentrating on productive processes".

\section{B. Practical Implications}

This contrastive study, no doubt, reveals the linguistic universals between the two languages, English and MSA. 
Although this study is essentially theoretical, it is valuable in the field of education. It shows the similarities and differences between the two languages, therefore it can predict the potential learning problems and difficulties that the learners of either language may encounter in the process of learning.

It is assumed that aspects of similarity will facilitate learning the foreign language, especially cognate words, or if a rule in L1 is identical to a rule in L2. Actually, in this respect English and MSA are not cognate languages and each has different noun-formation processes.

There are some words in common usage in MSA which do not create any problems or difficulties in learning English, such as telephone, thermometer, computer, UNESCO, etc., but these words are exceptions and we do not rely much on them, because these words represent the process of borrowing. But we rely mainly on the difficulties which the students may face while they learn English and they do not have the advantage of cognate features or similarities in noun-formation rules. Therefore, the following difficulties and errors are predicted:

a) In affixation

The MSA students are familiar with their noun-formation system in classifying the derivatives according to morphological patterns, and these patterns work as a matrix for forming new lexemes, but the case in English is different. For example, the following errors are possible:

1- Misapplication of the suffix 'er' which form agentive nouns:

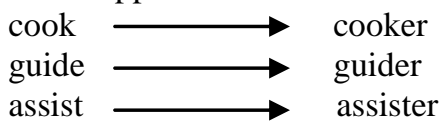

2- Misapplication of the suffix 'dom' which forms abstract nouns:

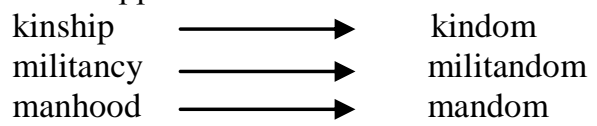

These are just expected examples of misapplication of the rule of affixation. The MSA student may transfer his language rules to the target language, as in the latter examples, or he may generalize the rule as in the former examples.

Thus, what errors the learner has committed in suffixes may also occur in prefixes, especially prefixes of negation.

b) In compounds

According to the different patterns of word order in both English and MSA, the following examples of errors are possible:

$\begin{array}{ll}\text { Housewife } & \longrightarrow \text { wifehouse } \\ \text { Space laboratory } & \longrightarrow \text { laboratory space }\end{array}$

c) In semantic relationships

The MSA student may use the superlative form longest instead of tallest as in:

Ali is the longest of the class (tallest).

This happens because MSA uses one word for both human beings and non-human things.

d) Wrong formation

Wrong formation may appear as in:

machine + er $\longrightarrow$ machineer (mechanic)

This example may refer to overgeneralization.

Likewise, the English learner of MSA may commit many errors in noun-formation when he wants to apply the rules.

For example, if he wants to apply the rule of the [af9al] from a trilateral verb, he may form it as:

Ali is more intelligent than Salih.

9li aðka ak $\theta$ ar min Salih.

This refers to the interference of language systems.

Many examples of errors and difficulties are expected, attributable to the differences between the two languages and their classification of noun-formation. The following brief points can indicate the difficulties the learners of both languages are expected to face:

- The misapplication of the rules in both languages.

- False analogy as in the former examples.

- Confusion between compounding and blending.

The MSA speaker who learns English will expect to make errors in conversion process as well as clipping, back formation, because they are unknown processes in his MT. The English learner who learns MSA may find it difficult to form the instrument noun, the patient noun, the adjunct noun, the locale and time nouns, simply because he is not familiar with them and therefore many errors are expected to be committed during the process of noun-formation.

The English speaker may also face a difficulty in comprehending the adjective as a noun in MSA, because he is used to forming it as an adjective not as a noun.

Finally, we can say that many of the errors could be attributed to two major sources, known in linguistics as interlingual (MT interference), and intralingual (overgeneralization of L2 rules; incomplete application of rules, etc.), besides other non-linguistic sources, such as methods of teaching, unqualified / untrained teachers and ineffective syllabus. 
Although the Arab and English linguists have compiled and codified the rules for noun-formation processes, some rules seem to be unclear or ambiguous and some processes do not seem to be rule-governed. The process of noun-formation is an effective aid to word-formation and consequently to increasing the corpus of the vocabulary of the language.

\section{REFERENCES}

[1] Abdut-t-Tawab, R. (1994). Fusu:lun fi-Fiqhi 1- luxha. Cairo: Maktabatu - Alkhangi.

[2] Aronoff, M. (1976). Word-Formation in Generative Grammar. Cambridge, Mass.: MIT Press.

[3] Bauer, L. (1983). English Word-Formation. Cambridge: Cambridge University Press.

[4] George, H. V. (1972). Common Errors in Language Learning: Rowley, Mass.: Newbury House.

[5] Hamid , A. S. (1997). Apposition in English and Arabic. Unpublished Ph. D. Thesis: Khartoum University.

[6] Hudson, G. (1985). Arabic Root and Pattern Morphology without Tears. Journal Linguistics. Vol.22, pp. 85-122

[7] Khaleel, H. (1978). Almuwallad. Alexandria: Alhay? atu - Almisriyatu Al9aammatu lil- Kitaab.

[8] Mahmoud, H. M. (1995). Concord in English and Arabic. Unpublished M. A. Thesis. Khartoum: Khartoum University.

[9] Matthews, P. H. (1972). Inflectional Morphology. Cambridge: Cambridge University Press.

[10] Matthews, P. H. (1991). Morphology.(2nd ed) Cambridge: Cambridge University Press.

[11] Thakur, D. (1997). Linguistics Simplified: Morphology. Patna: Bharati Bhawan Publishers and printers.

AbdulMahmoud Idrees Ibrahim was born in a small village in central Sudan in 11, July 1957. He has a Ph.D. in English Language (Applied Linguistics), Neelain University (2006),Sudan - M.A. in English and Linguistics, University of Yemen (1999) B.A. in Arts \& Education (English), University of Yemen (1997 - Professional Diploma of Education, Faculty of Education, Khartoum University (1987- Intermediate schoolteachers' Certificate, Bakht-er-Ruda Institute of Education (1981). He has many academic contributions- he compiled many course-books in linguistics \& applied linguistics as well as (ESP) courses, compiled \& instructional designed the following course-books for Open University of Sudan.- Writing skills 1 and writing skills 2 . He participated and attended many seminars, workshops, conferences and academic sessions in the educational field and English Language Teaching inside Sudan \& abroad.

Dr. AbdulMahmoud Idrees Ibrahim-Assistant professor - Now he is the Head, English Language Department, Faculty of Education, Alzaiem Alazhari University, Khartoum, Sudan. 